\title{
Possibility of Evolution in Culture of the Oryctes Nudivirus of the Coconut Rhinoceros Beetle Oryctes rhinoceros (Coleoptera: Scarabaeidae: Dynastinae)
}

\author{
Geoffrey 0. Bedford \\ Department of Biological Sciences, Macquarie University, NSW 2109, Australia \\ Email: geoffrey.bedford@mq.edu.au
}

How to cite this paper: Bedford, G.O. (2018) Possibility of Evolution in Culture of the Oryctes Nudivirus of the Coconut Rhinoceros Beetle Oryctes rhinoceros (Coleoptera: Scarabaeidae: Dynastinae). $A d$ vances in Entomology, 6, 27-33. https://doi.org/10.4236/ae.2018.61004

Received: December 14, 2017

Accepted: January 22, 2018

Published: January 25, 2018

Copyright $\odot 2018$ by author and Scientific Research Publishing Inc. This work is licensed under the Creative Commons Attribution International License (CC BY 4.0).

http://creativecommons.org/licenses/by/4.0/ (c) (i) Open Access

\begin{abstract}
It is suggested that the isolates of Oryctes Nudivirus (OrNV), cultured for decades in cells of Heteronychus arator (F.) (HA), be checked to verify genomic changes have not occurred which adapt them to culture but reduce or cancel their ability to infect the target pest, the coconut rhinoceros beetle (CRB), Oryctes rhinoceros (L.). Full genomes of field-caught OrNV isolates, and their infectivity against larvae and adults, could be compared with those of HA-cultured isolates. Further data to correlate OrNV dosage indices with doses in number of virions $/ \mathrm{ml}$ could be advantageous so as to explore if CRB larvae or adults may resist infection by a sub-threshold dose. Also the possibility of changes in the HA culture cells which alter the outer coat of the resulting virion, hence perhaps its infectivity towards CRB cells, could be checked. Might it be possible to move beyond HA-culture and develop tissue culture of Oryctes rhinoceros cells for mass production of OrNV as this beetle species is the target? Nuclear genomes of OrNV-resistant and OrNV-susceptible strains of the CRB could be examined for changes perhaps correlated with resistance. The possibility of endosymbiotic bacteria affecting CRB susceptibility to OrNV might be checked.
\end{abstract}

\section{Keywords}

Oryctes rhinoceros, Haplotype, Oryctes Nudivirus, OrNV,

Heteronychus arator, HA, Virion

\section{Introduction}

Oryctes rhinoceros (L.) (Coleoptera: Scarabaeidae: Dynastinae) is an important 
pest of coconut palms. The adults bore into the heart of the palm to feed on sap, damaging immature fronds which emerge subsequently showing typical $\mathrm{V}$-shaped cuts with reduced photosynthetic area. Repeated attacks may destroy the growing point and kill the palm. Young oil palms are also attacked and may be killed. While it is endemic in Asia, the pest had also been accidentally introduced into the South Pacific in the early $20^{\text {th }}$ century, and had then spread and become established in a number of South Pacific countries (summarised in [1] [2]).

An isolate of Oryctes Nudivirus (OrNV) was discovered in Malaysia and described in 1966 [3], and since then a number of other isolates have been investigated e.g. in India [4] [5], the Philippines [6], and Malaysia [7]. The OrNV virion is the infective unit which must survive in the environment and be transmitted naturally or by artificial dosages [1] [2] [8]. It is rod-shaped, with a viral membrane and capsid [8] enclosing a circular double-stranded DNA molecule for which the sequence of 127,615 bp (base-pairs) has been determined for a Malaysian isolate (Ma07 = Type B) [9]. Previously regarded as a Baculovirus, OrNV is now placed in the Nudivirus group [9].

Infection is peroral, and the virus multiplies in the fat body and midgut of larvae, and in the midgut of adults which defecate the virus and thus are "flying virus factories" which disseminate it [8]. Larvae dying from the infection contaminate breeding sites with OrNV, where other larvae become infected, and adults become infected by ingesting it there or during mating. However the virus is inactivated in the environment in a short time [2].

Since its discovery, OrNV has been released in CRB-affected South Pacific countries as a biopesticide/biocontrol pathogen against CRB, and from the 1970's particularly by releasing infected adults. As a biocontrol agent OrNV has been able to reduce and hold down beetle populations hence beetle damage to palms (summarised in [1] [2] [10]).

A recent informative contribution [11] has identified two haplotypes of CRB: CRB-S which is susceptible to OrNV and is the beetle genome widespread in the South Pacific plus certain Asian locations where it is endemic e.g. Malaysia; and CRB-G, resistant to OrNV, originally identified from Guam, and subsequently Port Moresby (Papua New Guinea), Solomon Islands, and Pearl Harbour (US) -which might be a genotype that has appeared more recently. The haplotypes are based on the COI mitochondrial genome.

The current article aims to build on this contribution by suggesting lines of investigation which may explore questions and advance the topic so as to enable continuing benefit to come from the use of OrNV. It is thus a commentary rather than giving new data.

\section{Commentary and Discussion}

Oryctes Nudivirus (OrNV) has been cultured in Heteronychus arator (F.) (HA) cells since 1981 [12] [13]. In HA tissue culture a replication cycle takes $12-16 \mathrm{~h}$ 
with much budding off of fresh OrNV virions at $16 \mathrm{~h}$ post-infection [14]. Most OrNV is produced \& released into the culture in the first $48 \mathrm{~h}$ post-infection [13].

In HA tissue culture the pathogen has no contact with cells of the target species (CRB) Oryctes rhinoceros. HA-cultured OrNV is the form in which the virus is produced and provided for testing against CRB, and for widespread release in the South Pacific. Might it be conceivable that with a replication cycle needing only hours, yet being in HA culture for 36 years, genomic changes may evolve in cultured OrNV strains or isolates adapting them so as to facilitate their ability to infect HA cells, but concomitantly reducing even disabling their ability to infect O. rhinoceros \& its midgut cells, as in HA cells this ability is thus redundant? While various isolates of OrNV can be readily produced in HA tissue culture [15] might the resulting OrNV product have undergone reduction (in relation to CRB-S) or even loss (in relation to $\mathrm{CRB}-\mathrm{G}$ ) in its ability to infect the target, $\mathrm{CRB}$ O. rhinoceros? (A recent case of a virus adapting to culture is the subtype H3N2 of the influenza virus which, grown in chicken eggs, mutates to adapt to grow better in that environment, but leaves the vaccine produced from it less effective for humans [16]).

The OrNV genome has plasticity, and is well able to undergo genome changes, which arise, establish, \& persist e.g. 12 isolates have been reported, with some even co-existing within the same geographical area e.g. Luzon, Philippines [6]. And in the Maldive Islands, 3 isolates were released, \& after 4 years, 3 new types of genomic change were recovered [17].

The CRB-G OrNV-resistant haplotype has been identified by bioassay peroral test feeding of OrNV to adult $O$. rhinoceros from the Guam population [11] what would be the result of feeding OrNV to larvae? Might there be a difference between Guam larvae \& adults in susceptibility to whatever OrNV isolate is tested, whether from natural sources or HA-produced? Prior to the HA-propagation method, OrNV had been propagated and produced in the South Pacific by infecting larvae perorally, and then adults were perorally infected with this crude OrNV suspension derived from larvae, and released [1]. In Sri Lanka ground-up midguts from virus-infected adults have been used to produce a suspension to perorally infect adults [18].

Also, the CRB-S populations of $O$. rhinoceros (established for many decades in South Pacific countries such as Samoa, American Samoa, Tonga, Fiji, Tokelau Isl, Wallis Isl, PNG (New Britain, New Ireland, Manus Isl) could be checked, both larvae, \& adults, as to their current susceptibility, to whatever OrNV strains may exist \& be isolated from larvae, \& adults, from current $O$. rhinoceros populations in those countries into which OrNV isolates have been released in decades past. Has this geographic and reproductive isolation begun to cause local differentiation in the genome of these CRB populations, perhaps affecting their susceptibility to OrNV [2]? Such results from susceptibility to field OrNV isolates could be compared to their susceptibility to various isolates of OrNV pro- 
duced by HA tissue culture \& currently available at present.

The CRB-G and CRB-S strains have so far been separated based on differences in the mitochondrial COI gene [11]. It would be of interest to look also for changes in the CRB nuclear genome which may be even more likely than the mtDNA to be correlated with susceptibility versus resistance to OrNV.

OrNV Malaysian geographical isolates A, B and C infecting larvae \& adults of Malaysian CRB-S have been propagated in HA [19] [20] and so far they retain their infectivity, but could this be due to relatively few replication cycles so far of these Malaysian OrNV genotypes in HA tissue culture, compared to decades of HA OrNV production in the South Pacific? What might happen if OrNV isolates $\mathrm{A}, \mathrm{B} \& \mathrm{C}$ are subject to prolonged culture in $\mathrm{HA}$ ?

Apart from possible genomic changes, another possibility may affect the coat of the virions. Fresh virions are shown in Figure 1, from [8]. When budded off from infected HA cells in culture, they are enclosed in a second or additionalunit membrane derived from the cell membrane of the host HA cell [14]. Might genomic changes have occurred over decades in the HA cell causing changes in its cell membrane hence the OrNV outer membrane, which may come to impede the OrNV virion's ability to infect $O$. rhinoceros cells?

A further consideration is that while it has been advocated [2] [21] [22] that it would be desirable that doses of OrNV used in inoculating of cultures or administered to CRB larvae or adults be expressed in units of number of virions $/ \mathrm{ml}$, in practice for all publications up to and including the present time this has not been possible. Instead, indices are used dating back to 1938 methodology [23], thus prior to modern virology, so the number of virions administered is not known. This may be relevant to the present-is there a minimum dose of OrNV virions below which a CRB larva or adult can fight off an infection? Will a CRB of any stage always succumb to whatever dose of OrNV virions that is ingested,
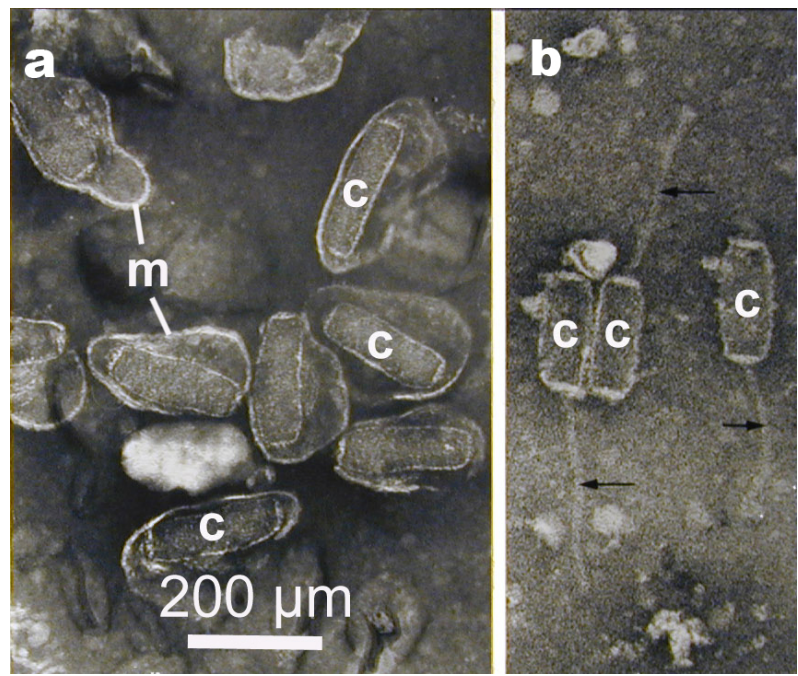

Source: With permission from A M Huger, J. Invertebrate. Pathology Vol. 89 (2005): 78-84.

Figure 1. Virions of Oryctes Nudivirus (OrNV). (a) Showing capsids [c] and viral membrane $[\mathrm{m}]$, (b) showing capsids [c]. 
or can its immune system fight off a potential infection from lower doses of virions?

One could check whether CRB-G may harbour an endosymbiont bacteria (perhaps paralleling Wolbachia?) which may give resistance to OrNV [24].

\section{Conclusion}

It would be worthwhile to compare the full genome of OrNV isolates freshly extracted from field populations of $O$. rhinoceros, with full genomes of OrNV long cultured in HA, to look for changes. Also the infectivity of these isolates against CRB larvae and adults could be compared with that of HA-cultured isolates. One could look into the possibility of establishing tissue culture of $O$. rhinoceros cells (thus moving beyond HA culture) for the propagation of OrNV isolates since $O$. rhinoceros is the ultimate target. The nuclear genome of CRB strains and geographical races could be checked for mutations which may affect resistance or susceptibility to OrNV.

\section{Acknowledgments}

I thank Prof. A. Hoffmann, University of Melbourne, Prof. E. Holmes, University of Sydney, and Prof. R. Frankham, Macquarie University, for helpful comments.

\section{Conflict of Interest}

There is no financial interest affecting this study.

\section{References}

[1] Bedford, G.O. (1980) Biology, Ecology, and Control of Palm Rhinoceros Beetles. Annual Review of Entomology, 25, 309-339. https://doi.org/10.1146/annurev.en.25.010180.001521

[2] Bedford, G.O. (2013) Biology and Management of Palm Dynastid Beetles: Recent Advances. Annual Review of Entomology, 58, 353-372. https://doi.org/10.1146/annurev-ento-120710-100547

[3] Huger, A.M. (1966) A Virus Disease of the Indian Rhinoceros Beetle, Oryctes rhinoceros (Linnaeus), Caused by a New Type of Insect Virus, Rhabdionvirus oryctes gen. n., sp. n. Journal of Invertebrate Pathology, 8, 38-51. https://doi.org/10.1016/0022-2011(66)90101-7

[4] Mohan, K.S., Jayapal, S.P. and Pillai, G.B. (1983) Baculovirus Disease in Oryctes rhinoceros Populations in Kerala. Journal of Plantation Crops, 11, 154-161.

[5] Gopal, M., Gupta, A., Sathiamma, B. and Nair, C.P.R. (2001) Control of the Coconut Pest Oryctes rhinoceros L. Using the Oryctes Virus. Insect Science Applications, 21, 93-101. https://doi.org/10.1017/S1742758400020142

[6] Crawford, A.M., Zelazny, B. and Alfiler, A.R. (1986) Genotypic Variation in Geographical Isolates of Oryctes Baculovirus. Journal of General Virology, 67, 949-952. https://doi.org/10.1099/0022-1317-67-5-949

[7] Ramle, M., Wahid, B., Norman, K., Glare, T.R. and Jackson, T.A. (2005) The Incidence and Use of Oryctes Virus for Control of Rhinoceros Beetle in Oil Palm Plan- 
tations in Malaysia. Journal of Invertebrate Pathology, 89, 85-90. https://doi.org/10.1016/j.jip.2005.02.009

[8] Huger, A.M. (2005) The Oryctes Virus: Its Detection, Identification, and Implementation in Biological Control of the Coconut Palm Rhinoceros Beetle, Oryctes rhinoceros (Coleoptera: Scarabaeidae). Journal of Invertebrate Pathology, 89, 78-84. https://doi.org/10.1016/j.jip.2005.02.010

[9] Wang, Y., Kleespies, R.G., Ramle, M.B. and Jehle, J.A. (2008) Sequencing of the Large dsDNA Genome of Oryctes rhinoceros Nudivirus Using Multiple Displacement Amplification of Nanogram Amounts of Virus DNA. Journal of Virological Methods, 152, 106-108. https://doi.org/10.1016/j.jviromet.2008.06.003

[10] Bedford, G.O. (2013) Long-term Reduction in Damage by Rhinoceros Beetle Oryctes rhinoceros (L.) (Coleoptera: Scarabaeidae: Dynastinae) to Coconut Palms at Oryctes Nudivirus Release Sites on Viti Levu, Fiji. African Journal of Agricultural Research, 8, 6422-6425.

[11] Marshall, S.D.G., Moore, A.A.A., Vaqalo, M., Noble, A. and Jackson, T.A. (2017) A New Haplotype of the Coconut Rhinoceros Beetle, Oryctes rhinoceros, Has Escaped Biological Control by Oryctes rhinoceros Nudivirus and Is Invading Pacific Islands. Journal of Invertebrate Pathology, 149, 127-134. https://doi.org/10.1016/j.jip.2017.07.006

[12] Crawford, A.M. (1981) Attempts to Obtain Oryctes Baculovirus Replication in 3 Insect Cell Cultures. Virology, 112, 625-633. https://doi.org/10.1016/0042-6822(81)90307-X

[13] Crawford, A.M. and Granados, R.R. (1982) Nonoccluded Baculoviruses. Proceedings of the $3^{\text {rd }}$ International Colloquium on Invertebrate Pathology, Univ. of Sussex, Brighton, 6-10 September 1982, 154-159.

[14] Crawford, A.M. and Sheehan, C. (1985) Replication of Oryctes Baculovirus in Cell Culture: Viral Morphogenesis, Infectivity \& Protein Synthesis. Journal of General Virology, 66, 529-539. https://doi.org/10.1099/0022-1317-66-3-529

[15] Pushparajan, C., Marshall, S.D.G., Claus, J.D. and Visnovsky, G. (2013) Characterization of Growth and Oryctes rhinoceros Nudivirus Production in Attached Cultures of the DSIR-HA-1179 Coleopteran Insect Cell Line. Cytotechnology, 65, 1003-1016. https://doi.org/10.1007/s10616-013-9632-9

[16] Scripps Research Institute (2017) How Flu Shot Manufacturing Forces Influenza to Mutate: Egg-Based Production Causes Virus to Target Bird Cells, Making Vaccine Less Effective. ScienceDaily. ScienceDaily, 30 October 2017. http://www.sciencedaily.com/releases/2017/10/171030134625.htm

[17] Crawford, A.M. and Zelazny, B. (1990) Evolution in Oryctes Baculovirus: Rate and Types of Genomic Change. Virology, 174, 294-298. https://doi.org/10.1016/0042-6822(90)90078-6

[18] Jayawardena, S.P. (2013) Effective Inoculation Method and Optimum Concentration of Oryctes Virus to Infect Oryctes rhinoceros Adults. European International Journal of Science and Technology, 2, 188-194.

[19] Khudri, N.A.F.R.S., Azmi, W.A., Moslim, R., Kamarudin, N. and Ali, S.R.A. (2016) Infectivity of Oryctes Nudivirus Produced on Cell Culture DSIR HA-1179 against Larvae and Its Effects on Feeding of Neonates of Rhinoceros Beetle, Oryctes rhinoceros. Journal of Oil Palm Research, 28, 256-265. https://doi.org/10.21894/jopr.2016.2803.03

[20] Khudri, N.A.F.R.S., Azmi, W.A., Kamarudin, N., Ali, S.R.A. and Moslim, R. (2016) Replication of Oryctes Nudivirus (OrNV) in Insect Cell Line DSIR-HA-1179 and Its 
Infectivity on Neonates of Rhinoceros Beetle, Oryctes rhinoceros. Journal of Oil Palm Research, 28, 452-462. https://doi.org/10.21894/jopr.2016.2804.06

[21] Jackson, T.A., Crawford, A.M. and Glare, T.R. (2005) Oryctes Virus: Time for a New Look at a Useful Biocontrol Agent. Journal of Invertebrate Pathology, 89, 91-94. https://doi.org/10.1016/j.jip.2005.03.009

[22] Bedford, G.O. (2014) Advances in the Control of Rhinoceros Beetle Oryctes rhinoceros in Oil Palm. Journal of Oil Palm Research, 26, 183-194.

[23] Reed, L.J. and Muench, H. (1938) A Simple Method of Estimating 50\% Endpoints. American Journal of Epidemiology, 27, 493-497. https://doi.org/10.1093/oxfordjournals.aje.a118408

[24] Hedges, L.M., Brownlie, J.C., O’Neill, S.L. and Johnson, K.N. (2008) Wolbachia and Virus Protection in Insects. Science, 322, 702.

https://doi.org/10.1126/science. 1162418 